\title{
Effect of Thiobenzoate on Cytology of Candida albicans
}

\author{
By G. R. GALE AND HELEN H. MCLAIN \\ The Veterans Administration Hospital, The Department of Physiology and \\ Pharmacology, and the Department of Pathology, Duke University \\ Medical Center, Durham, North Carolina
}

(Received 11 March 1964)

\begin{abstract}
SUMMARY
Cytological changes in Candida albicans, associated with exposure to the antimicrobial agent thiobenzoate, were investigated with the electron microscope. After incubation of proliferating cells for 2-3 hr with the inhibitor, the nucleus displayed a lessened electron density. Following this, gaps appeared in the nuclear membrane and canaliculi emanated toward the periphery of the cell. Complete loss of cytoplasmic organization appeared to be the terminal event. These changes were shown to differ from those incurred during autolysis, induced either by substrate deprivation by washing, or by a combination of substrate deprivation and accumulation of metabolic products in an ageing culture.
\end{abstract}

\section{INTRODUCTION}

The sulphur-containing antifungal peptide Ro 2-7758 (Hoffman-LaRoche) has been shown to inhibit the microbial sulphate reduction system (Gale, Kendall \& Welch, 1963) and to induce a marked thickening of the cell wall of Mucor corymbifera (Gale, 1963a). However, the discrepancies between the in vitro and in vivo activities of Ro 2-7758, along with its limited antimicrobial spectrum, make conclusions tenuous in attempting to correlate biochemical and cytological data regarding its mechanism of action. As a result of those observations, a group of sulphur-containing synthetic aromatic compounds was investigated to determine whether certain other sulphur-containing compounds inhibit the microbial sulphate reduction system and, if so, whether these compounds inhibit microbial growth. Certain pharmacological properties of thiobenzoic acid and its $o$-fluoro- and $m$ fluoro-derivatives have been reported (Gale, Kendall \& Bernheim, 1964). These compounds are initially fungistatic to Candida albicans, with death of the cells occurring some hours after the fungistatic action is manifest. Evidence was presented which implicates inhibition of the microbial sulphate reduction system as the fundamental mechanism of antimicrobial action.

The present paper reports on cytological alterations which occurred in Candida albicans in the presence of thiobenzoate.

\section{METHODS}

The strain of Candida albicans used and the methods of growth and fixation were as described previously (Gale, 1963b) except that uranyl nitrate was used as a postfixative according to the method of Vitols, North \& Linnane (1961). Thio- 
benzoic acid (Aldrich Chemical Co., Milwaukee, Wis., U.S.A.) was neutralized as described earlier (Gale et al. 1964) and added to a $16 \mathrm{hr}$ Sabouraud broth culture of the test organism to final concentration $1000 \mu \mathrm{g} . / \mathrm{ml}$. (Bacto-Sabouraud liquid medium, Difco Laboratories, Detroit, Mich., U.S.A.). Samples were taken at intervals for fixation, following which they were embedded in methacrylate (a 30/80 mixture of ethyl + butyl monomers) containing $0.2 \%$ uranyl nitrate (Ward, 1958) and polymerized at $60^{\circ}$. Sections were cut with glass knives on a PorterBlum microtome and examined in an RCA EMU 3-F electron microscope, using $50 \mathrm{kV}$. accelerating voltage through a $30 \mu$ objective aperture.

\section{RESULTS}

Control cells of Candida albicans were comparable to those described in an earlier report (Gale, 1963b), and similar to the preparations of Saccharomyces cerevisiae described by Vitols et al. (1961), with the exception that large vacuoles with welldefined limiting membranes were seen only rarely. A comparison with the earlier report (Gale, $1963 b$ ) clearly shows the advantages of using uranyl nitrate as a postfixative following permanganate fixation of yeast-like organisms which are not well preserved with osmium tetraoxide (Gale, $1963 \mathrm{~b}$; Vitols et al. 1961). A typical specimen is shown in Pl. 1, fig. 1, displaying the cell wall of varying electron density, the invaginating cytoplasmic membrane, mitochondria with cristae, a nucleus with a typical unit membrane, and an area suggestive of a small vacuole. The granular nucleus shows areas of lesser electron density as was also described in S. cerevisiae (Vitols et al. 1961).

Proliferating cells to which thiobenzoate was added remained virtually indistinguishable from control cells for approximately $2 \mathrm{hr}$. Since the fungistatic action of this compound is manifest immediately rather than after a latent period (Gale et al. 1964), it must be concluded that the arrest of growth per se is unaccompanied by a resolvable cytological lesion. After further incubation for $\mathbf{2 - 3} \mathrm{hr}$, however, aberrations in cell structure became evident in a large percentage of the cells, progress of which is shown in $\mathrm{Pl}$. 1, 2, figs. 2-4. The initial perceptible change was a lessened electron density of the nucleus. Following this there appeared gaps in the nuclear membrane, from which canaliculi emanated toward the periphery of the cell. A lessened electron density of mitochondria was noted frequently. Upon extension of the canaliculi to the periphery there was apparently some loss of integrity of the cell wall; the complete absence of cell wall material in some areas is probably an artifact of fixation, since it seems unlikely that an altered spheroplast in broth culture would remain in a cell wall with such a defect. Cytoplasm of thiobenzoate-treated cells seemed to have a greater electron density, but no marked changes were noted in granularity. A compromised cell wall would perhaps facilitate passage of uranyl ions into the cytoplasm to confer the enhanced density.

Even in the samples which were fixed after incubation for $3 \mathrm{hr}$ with thiobenzoate, a small percentage of the cells retained all appearances of normal control cells. Previous work with thiobenzoate (Gale et al. 1964) showed that death of $100 \%$ of the cell population in a proliferating culture of Candida albicans did not occur until between 10 and $12 \mathrm{hr}$ after addition of the inhibitor to a final concentration of $1000 \mu \mathrm{g} . / \mathrm{ml}$. Although quantitative plate counts were not made at intervals in that 
study, it seems reasonable to assume that time of death occurred with the usual standard distribution within the population. Since fungistasis induced by thiobenzoate was immediate in onset (Gale et al. 1964), an attempt was made to determine whether changes observed in thiobenzoate-treated cells were in any way similar to changes occurring in autolysing cells.

Autolysis may be induced in two ways: washed, non-proliferating cells may be incubated in a non-nutrient medium; or a cell population in a nutrient medium may be incubated for a time beyond the point at which population density is maximal. In the former case, cessation of growth and ultimate cell deterioration is due primarily to substrate depletion through washing. In the latter case, depletion of substrate and accumulation of metabolic end products presumably are both contributory factors. Consequently, the cytological changes which accompany autolysis induced in each manner were investigated.

Samples for fixation were taken aseptically at intervals from a growing culture of Candida albicans during a period of $120 \mathrm{hr}$; the growth curve of the culture as shown by optical density measurements levelled off after incubation for about $40 \mathrm{hr}$. A typical autolysing cell is shown in Pl. 2, fig. 5. The initial change consisted of loss of nuclear and mitochondrial membranes. Nuclear material remained cytologically distinguishable for a time, however, being detectable by a slight difference in granularity as compared with the surrounding cytoplasm. The event of cell disintegration was undoubtedly a rapid one, since no cells were observed which displayed a stage intermediate between that just described and that shown in Pl. 2, fig. 4. The cytological events of autolysis in an ageing culture thus appeared different from those which occurred during treatment with thiobenzoate.

A $16 \mathrm{hr}$ culture of Candida albicans was washed three times with $0 \cdot 1 \mathrm{M}$-sodium potassium phosphate buffer $(\mathrm{pH} \mathrm{7 \cdot 4)}$ to remove nutrient materials. After suspending the sedimented pellet of cells to the original volume in buffer, the suspension was returned to the incubator $\left(37^{\circ}\right)$ and samples removed at intervals for fixation. Changes were not observed until about $4 \mathrm{hr}$ after washing and were not as consistent as those observed in the ageing autolysing culture. The most frequently observed forms were cells in which cytoplasm had shrunk markedly from the cell wall. Nuclei and mitochondria were usually intact until the event of complete cell disintegration occurred (Pl. 2, fig. 6). In spite of the greater variety of forms observed, it was clear that autolysis which occurred under substrate deprivation did not bear any resemblance to initial cytological changes which accompany thiobenzoate treatment.

\section{DISCUSSION}

Evidence presented here and in a preceding paper (Gale et al. 1964) indicates that the antimicrobial action of thiobenzoate against Candida albicans consists of at least two components. First of these is a fungistatic action manifest by cessation of replication of cells of an actively growing culture immediately upon addition of inhibitor. This action is unaccompanied by any observable cytological lesion and can be annulled for a time by washing the cells with a large volume of water and plating on fresh medium. The second component, irreversible cell damage, is time dependent and occurs only in proliferating cells; cells previously washed and then exposed to thiobenzoate in a nutrient-free medium were not killed within a $12 \mathrm{hr}$ 
period (Gale et al. 1964). The initial fungistasis may be explained on a nutritional deprivation induced by the inhibitor, that is, a block in metabolism of some compound(s) required for normal growth. Inhibition of the microbial sulphate reduction system, previously suggested as the primary mechanism of action of thiobenzoate and its $o$-fluoro- and $m$-fluoro-derivatives (Gale $e t$ al. 1964), is one way in which such a nutritional deprivation could be imposed. In intact cells the fungistatic mechanism is obviously reversible, as shown by survival of cells after removal of the inhibitor by washing.

The terminal cytological manifestation of cell damage due to thiobenzoate is apparently a lytic phenomenon, as evidenced by the similarity in appearance of drug-treated and autolysing cells after complete loss of cytoplasmic organization. Events leading to lysis, however, appear to be quite different in the two cases. Whereas initial autolytic changes in an ageing culture consist of loss of mitochondrial and nuclear membranes, and autolysing washed cells showed principally retraction of cytoplasm with a maintenance of membranes, changes induced by thiobenzoate primarily originate in the nucleus. If the hypothesis of mechanism of action of thiobenzoate on the sulphate reduction system is substantiated, the relationship of sulphur metabolism to nuclear organization remains to be clarified.

This work was aided by Grant GM-09389 from the National Institutes of Health, United States Public Health Service.

\section{REFERENCES}

Gale, G. R. (1963a). Effects of the antifungal peptide Ro 2-7758 on morphology of Mucor corymbifera. J. Bact. 85, 833.

Gale, G. R. (1963b). Cytology of Candida albicans as influenced by drugs acting on the cytoplasmic membrane. J. Bact. 86, 151.

Gale, G. R., Kendall, S. M. \& Bernhem, F. (1964). Antimicrobial activity of thiobenzoate and its $o$-fluoro- and $m$-fluoro-derivatives. Proc. Soc. exp. biol., N.Y. 115, 198.

Gale, G. R., Kendall, S. M. \& Welch, A. M. (1963). Observations on mechanism of action of the anti-fungal peptide, Ro 2-7758. Proc. Soc. exp. biol., N.Y. 113, 179.

Vitols, E., North, R. J. \& Linnane, A. W. (1961). Studies on the oxidative metabolism of Saccharomyces cerevisiae. I. Observations on the fine structure of the yeast cell. J. biophys. biochem. Cytol. 9, 689.

WARD, R. T. (1958). Prevention of polymerization damage in methacrylate embedding media. J. Histochem. Cytochem. 6, 398.

\section{EXPLANATION OF PLATES}

The following abbreviations are used: $\mathbf{C W}$, cell wall; $\mathbf{C M}$, cytoplasmic membrane; $\mathbf{N}$, nucleus ; M, mitochondrion; NM, nuclear membrane; V, vacuole. The line in each figure indicates $1 \cdot 0 \mu$.

Figs. 2-4. Cells of Candida albicans after exposure to $1000 \mu \mathrm{g}$. thiobenzoate/ml., in Sabouraud broth.

\section{Plate 1}

Fig. 1. Control cell of Candida albicans undergoing division. $\times 26,000$.

Fig. 2. After $2 \mathrm{hr}$ exposure, nuclear integrity is lost and gaps appear in the nuclear membrane. $\times \mathbf{3 0 , 0 0 0}$.

Fig. 3. After $3 \mathrm{hr}$ exposure, canaliculi radiate from the nucleus to the periphery of the cell. Cytoplasm has partially retracted while the cytoplasmic membrane appears to remain associated with the cell wall. $\times 30,000$. 

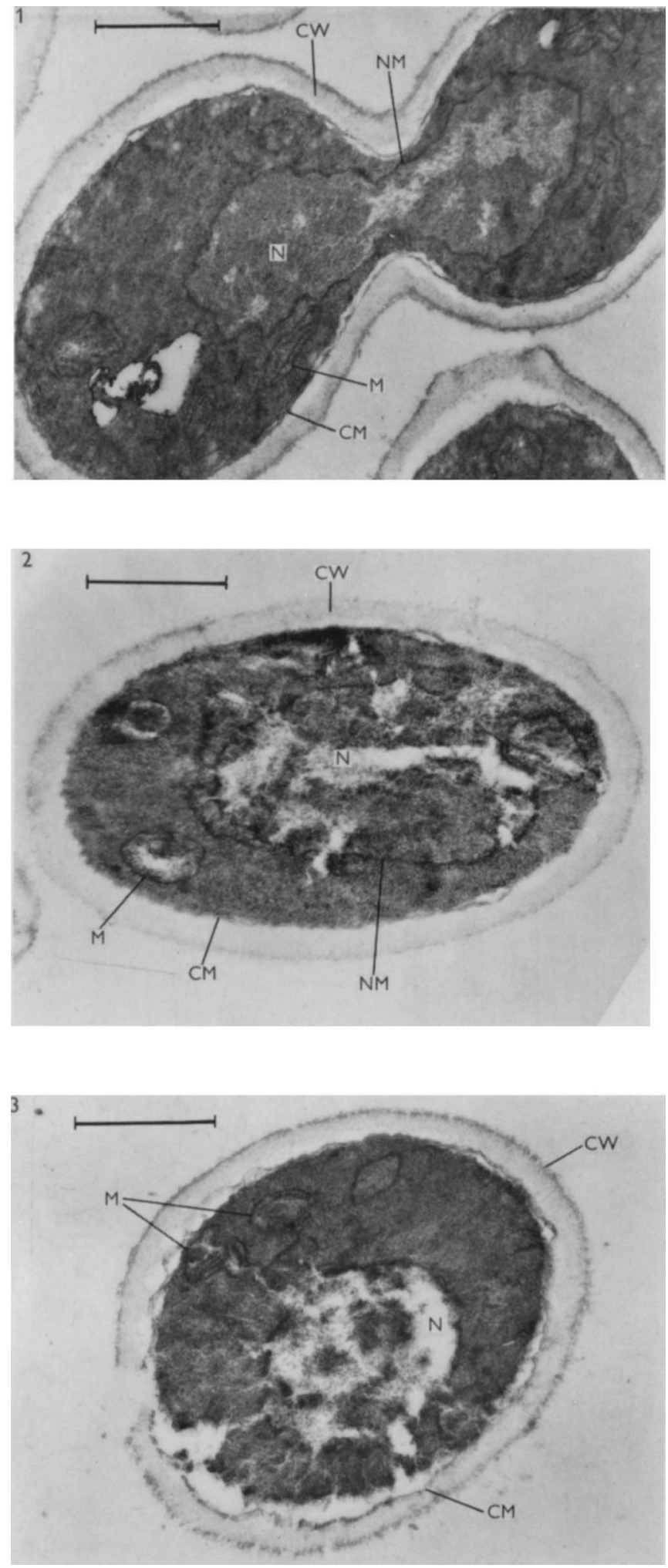

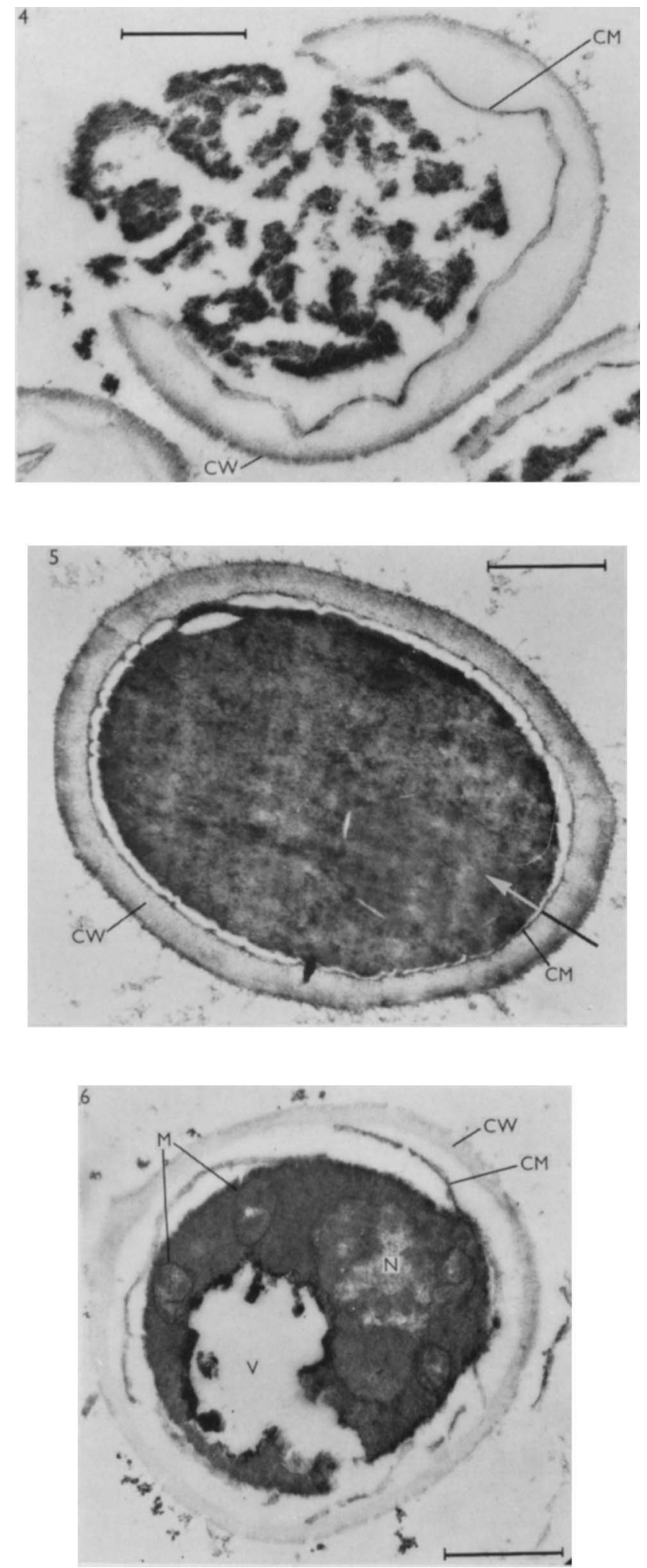


\section{Plate 2}

Fig. 4. After 4 hr exposure, cytoplasm is completely disorganized and no intracellular organelles can be differentiated. $\times 26,000$.

Fig. 5. Cell of Candida albicans from a $66 \mathrm{hr}$ culture in Sabouraud broth. The nuclear membrane cannot be detected, but the nucleus can still be differentiated by a slight difference in granularity

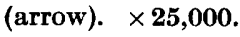

Fig. 6. Cell of Candida albicans after exposure to a non-nutritional environment for $4 \mathrm{hr}$. Preautolytic changes consist of cytoplasmic retraction with disruption of the cytoplasmic membrane. The nucleus and mitochondria are intact. Large vacuoles were seen frequently under these conditions. $\times 25,000$. 